\title{
Motivation in a Flipped Classroom, a Case Study of Teaching Oral English in a Vocational College in Mainland China
}

\author{
ZUO Xin-yue \\ College of Education, University of Massachusetts Amherst, Amherst, USA
}

\begin{abstract}
This action research explores the use of the flipped classroom approach in an English speaking class with 25 students at intermediate level in a vocational college in mainland China. It aims at motivating English learners and helping them develop communicative language skills more effectively and efficiently. Both qualitative and quantitative methods are adopted to analyze the data collected through interviews, teaching logs, as well as anonymous questionnaires and a summative assessment. Results show that the flipped classroom approach does stimulate students to invest more time and effort prior to instruction and during class learners do participate in communicative language exercises more enthusiastically. As a result, conceivable progress has been made in learners' performance. Possible recommendations of incorporating periodic rotation within the class, adding certain teacher-led instruction, and informal evaluation with group members, are raised at the end of the paper to help further improve the teaching/learning outcome of the flipped classroom approach.
\end{abstract}

Keywords: English speaking, motivation, flipped classroom, English language teaching

\section{Introduction}

I came up with this research topic while I was observing an English speaking class in a Chinese college and also from my personal English learning experiences. Back in China, oral speaking instruction usually takes the empty-vessel approach, with the teacher almost serving as the only resource for students, and functioning as a transmitter of knowledge. Students, however, as passive receivers, take in all the information unquestionably. Especially in speaking class; learners practice their communicative skills mainly through repeated drilling and memorizing fixed sentence patterns. Chances for other meaningful interactions and exercises are rare. Clearly, since students could easily get tired of such a fossilized method, gradually some of them lose interest in English learning. The improvement of their speaking skills is thus stymied. To help address the problem, the flipped classroom approach is tried, aiming at motivating learners to further strengthen their oral capabilities, and making English speaking instruction in China more conductive and efficient. The research question of the study is: Is the flipped classroom approach effective in motivating students and improving their speaking skills?

The current research took place in an English as a foreign language (EFL) class in Suzhou Jianxiong Institute of Technology in China, with altogether 25 students at low-intermediate level and a host teacher. The main objective of the course is to prepare learners for their future vocational development. And students are required to master some basic workplace English necessary for their future job.

ZUO Xin-yue, Ph.D. student, College of Education, University of Massachusetts Amherst. 


\section{Methods and Data Collection Strategies}

After carefully analyzing researches and publications in this field, the researcher developed the following steps for the implementation of the flipped classroom approach. Students were divided into groups or pairs, and signed a placement sheet at the beginning stage. The instructor would distribute or post learning materials for the next class by the end of each class, and learners are required to carry out groups study, sharing their confusions and discussing intriguing points about the learning materials before class time. During instruction, the teacher would first evaluate the student' $\mathrm{s}$ autonomous learning by asking checking questions closely related to the materials given, and then, give a brief summary of the knowledge and skills covered. Next, the students would be asked to carry out diverse practice activities and tasks, including role plays, situational dialogues, or short speeches to create opportunities for real language use. The teacher would assess the students' performance throughout the process, and offer additional instructive support or scaffolding accordingly.

Over a course of 12 weeks, four teaching logs, three short video clips and two interviews in written form related to the experiment were collected periodically to help identify and delineate students' actual class performance after developing the flipped classroom pedagogy. Additionally, at the end of the semester, students took part in an anonymous survey constructed by the researcher centering on self-analyzing respondents' English learning motivation, and their general attitudes towards group work and language practice. Finally, a mandatory oral speaking test was given to the 25 students.

Both qualitative and quantitative analyses are used to explore the effectiveness of the flipped classroom approach adopted in the research.

As a surrogate to the traditional empty vessel approach, the flipped classroom method, which possesses a sound theoretical backup, is coherent and rational in nature. Furthermore, since all the data amassed are original and pristine, and the findings are fully grounded on the information carefully gathered at first hand, the validity of this study is secured.

One of the most significant drawbacks of the current research is the limited time slot, which hinders the researcher to keep track of the subjects' English learning further and proffer more first-hand data for analyzing. And thus, some of the findings and suggestions may not be sound enough. Besides, as a pilot experiment, the teaching approach used in the research may not work well under different class settings, especially when it comes to the teaching of youngsters who are not well disciplined and educated to carry out independent pre-class learning and take care of their own learning without constant scaffolding from instructors. The limited quantitative data collected might impair the objectivity as well.

\section{Findings and Implications}

\section{Teaching Log, Interview, and Video Findings}

According to the teaching log and my interviews (see Appendix) with the host teacher, before conducting the experiment, few students could answer questions raised related to the learning material, and therefore, a host of class time is allotted to lecturing language points. In this case, little time could be devoted to oral practice. Now, thanks to the pre-class learning, more students could proffer reasonable answers to the teacher's questions and provide useful information on certain topics. Thus, more class time is devoted to language practice. In addition, before the experiment, some students would always play with their cell phones, but now they rarely skive off from tasks. Besides, the classroom atmosphere has become more active with many more 
students getting involved in learning activities. Also, the students are now better motivated, as is indicated by one of the four teaching logs, which reads,

During the break, two students asked me for more advice on improving their oral speaking skills. They told me they are much inspired by my present teaching method, which offers them more opportunity to practice oral English... They also told me they are more confident now and are not afraid of speaking English in class.

The video clips shot in class also reveal the above mentioned changes. Teacher dominating classroom and lecturing, one of the most common classroom practices in China, stops existing any more in the video. More students volunteer to participate in classroom communicative exercises, and invest their personal ideas into dialogues.

Clearly, posing tasks and giving students ample chances for collaborative practices helps motivate learners (Ormrod, 2013).

\section{Survey Findings}

All together, 25 questionnaires were distributed to the subject class, and the researcher got 25 effective pieces back. Figure 1 to Figure 8 below show the results of the eight survey questions (see Appendix).

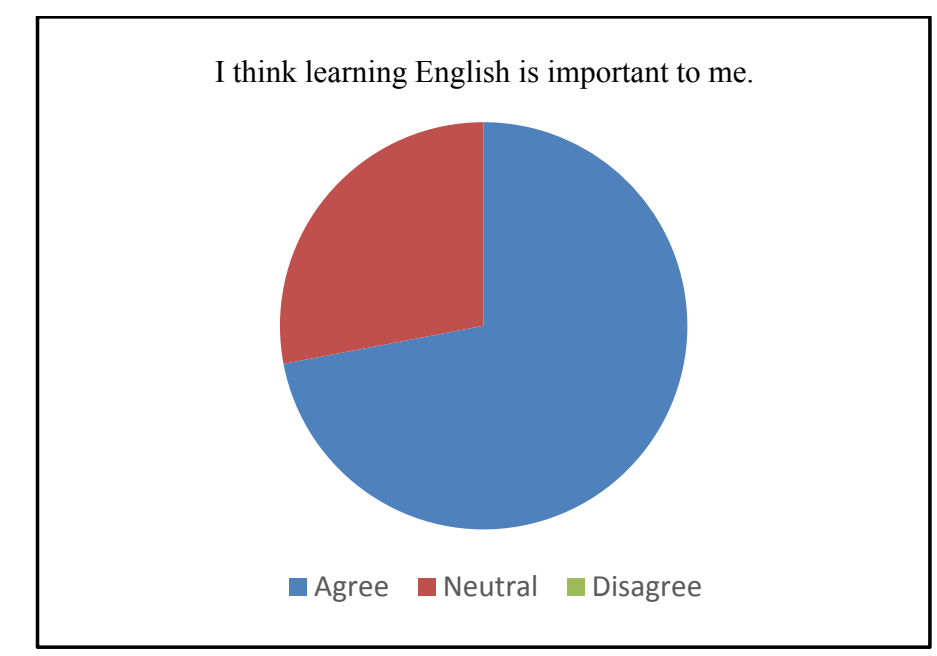

Figure 1. Results of survey question 1.

I am willing to further my English study.

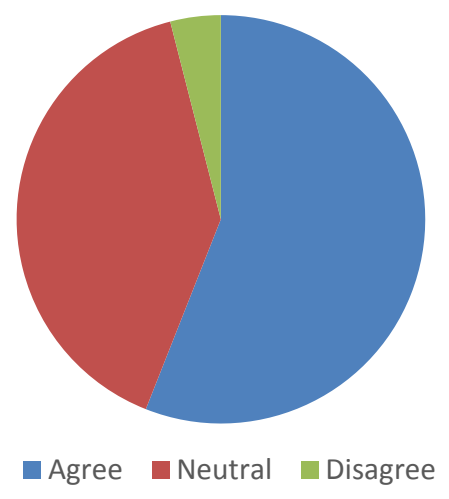

Figure 2. Results of survey question 2. 
I benefit a lot during group/pair study prior to class.

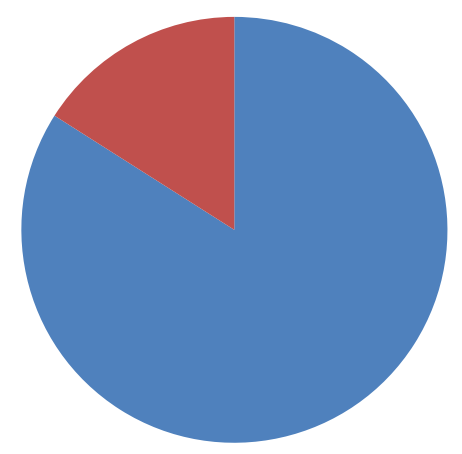

Agree $\quad$ Neutral Disagree

Figure 3. Results of survey question 3.

I like to participate in class activities.

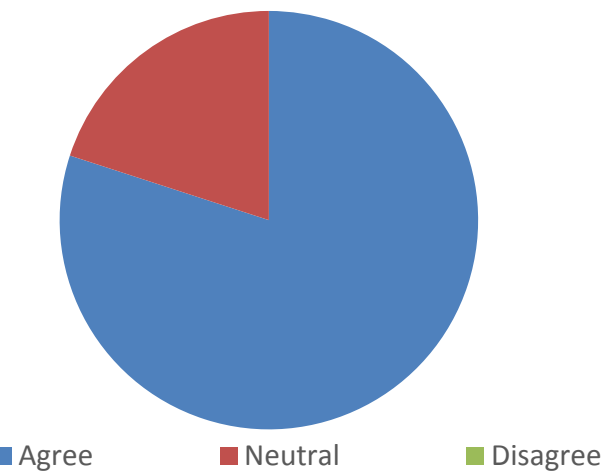

Figure 4. Results of survey question 4.

I have more opportunities to practice English during the class than before.

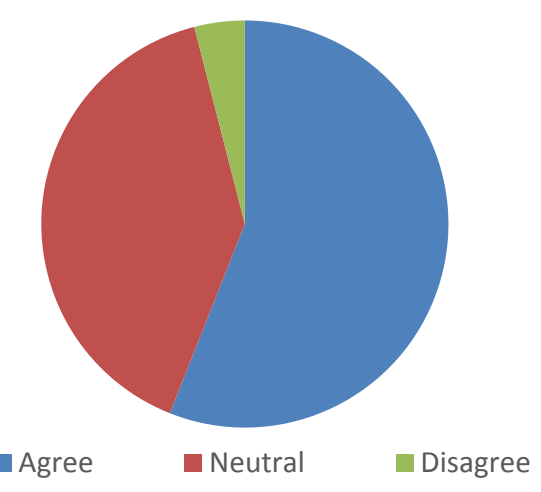

Figure 5. Results of survey question 5. 
I am more concentrated on the instruction in the class presently.

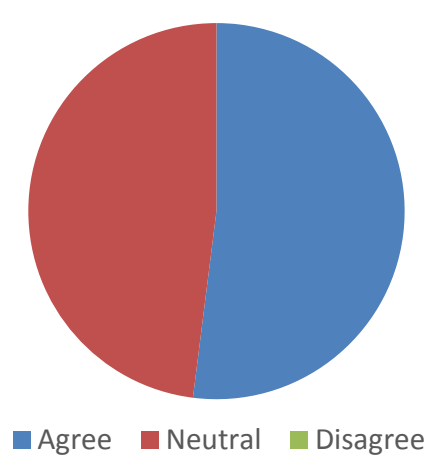

Figure 6. Results of survey question 6.

My spoken English improves after adopting this new strategy.

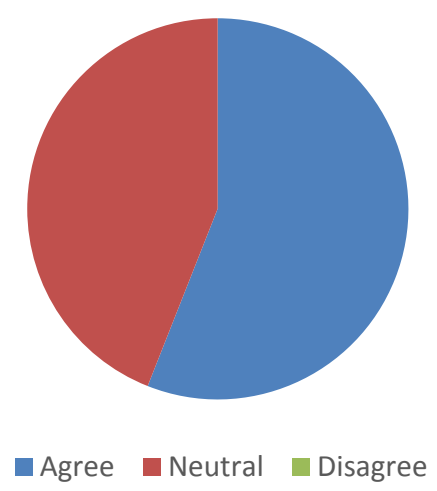

Figure 7. Results of survey question 7.

I would recommend this kind of teaching approach.

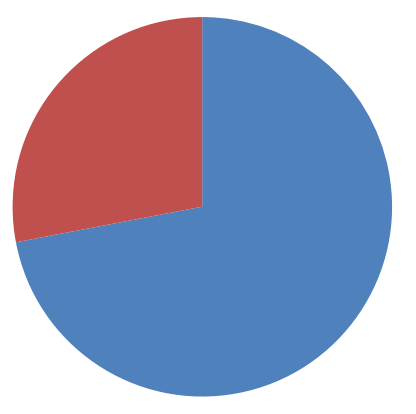

agree $\quad$ Neutral $\quad$ Disagree

Figure 8. Results of survey question 8 . 
Concretely, Figure 1 reveals that over $70 \%$ of the students think English significant to their life and Figure 2 indicates that $56 \%$ of them hope to perfect their English language capabilities furthermore. In addition, $84 \%$ of the subjects view group/pair work prior to class positively; $80 \%$ of them like to take part in the interactive class activities; and 56\% of them agree that they are given much more chances to practice English during class (see Figures 3, 4, \& 5). Moreover, $58 \%$ of all the respondents feel more concentrated in class, and $56 \%$ of them could identify their enhancement in English performance (see Figures $6 \& 7$ ). Finally, Figure 8 tells us $72 \%$ of the learners express their willingness to recommend the flipped approach. Overall, the survey findings correspond to what are revealed from the teaching logs, written interviews, and videos. Obviously, through the survey, the students expressed their approbation of the flipped classroom approach and confirmed the changes brought about by the approach.

\section{Test Result Findings}

Altogether 25 students took the oral test on June 29. The test is made up of three parts, Part 1 Question (20 points), Part 2 Reading Aloud (10 points), and Part 3 Dialog (20 points), with a total score of 50.

Table 1

The Average Total Scores of the Oral Test

\begin{tabular}{lll}
\hline Average total scores & Student number & Percentage \\
\hline $36-39$ & 4 & $16 \%$ \\
$40-44$ & 17 & $68 \%$ \\
$45-46$ & 4 & $16 \%$ \\
\hline
\end{tabular}

As is revealed in Table 1, the average total score of the class is 41.8 points. Twenty-one of the students (about 84\%) get a score of 40 or above and only four students' marks fall between 36 and 39 . Therefore, the test results are really encouraging and satisfactory, showing a general good mastery of the skills covered. According to the host teacher, the students achieved far less last semester, even with some failing the oral test (the previous speaking test results are unavailable due to privacy).

\section{Implications}

According to the findings above mentioned, it is safe to conclude that the flipped classroom approach adopted in the research is effective in motivating the students and improving their speaking skills. This action research provides some pedagogical implications for Chinese English instruction.

First of all, teaching should be student-centered. Teachers' domination of class does little in helping learners improve their language skills, since "good teaching can't happen without student learning" (n.d.). Therefore, designing the flow of instruction with an emphasis on students' participation and involvement is extremely important to language class. Under the flipped classroom approach, students perform as autonomous monitors of their own learning, rather than being passive recipients of knowledge, so this approach is conductive to the development of students' language skills.

Secondly, teachers should do their utmost to cultivate learners' autonomous learning abilities. Class time is quite limited, so it is impossible for a learner to master a language only through classroom learning. Learning outside of class is essential. The flipped classroom approach encourages learners to spend extra time and effort before class, so no wonder it is more efficient.

Besides, group work ought to be largely advocated. According to Senior (2002) "if language learning is a collective endeavor, then learning takes place most effectively when language classes pull together as unified 
groups" (p. 403), group study enables learners to work collaboratively, striving to add their own contribution to the whole team and taking care of other learners' efforts as well. And this is just what the present research demonstrates.

Lastly, to effectively develop learners' oral skills, large amount of exercises is indispensible. Plainly taking notes and memorizing sentence patterns would not help in increasing students' speaking proficiency. Therefore, various language practice activities and tasks ought to be incorporated in class, for instances, brain storming, storytelling, mock, and situational dialogues, in order to maximize chances for language use. The fatal weakness of the traditional teaching method lies in the fact that it fails to create such opportunities.

\section{Recommendations}

In regard to group and pair work, the current practice is asking students to fill out a placement sheet at the beginning of the experiment, and thus, they will collaborate with certain students the whole semester. Advantages such as motivating introvert students and being easy to initiate work are apparent. However, I would encourage periodic rotation within the class, particularly within groups that encompass learners with extreme gaps, and those who do not work harmoniously because of discrepancies in learning styles. Since according to Allport (1954) and Pettigrew (1998), effective group work entails four key components-equality among group members, shared targeting goals, collaborative working, and assistance from authorities, it is advisable that the instructor refines classroom seating arrangement from time to time especially when problems occur. In this way, students could get to each other well, expose to more comprehensive and creative idea, and have better chances for information exchange.

Also, it should be pointed out that particular topics deserve additional teacher-led instruction. For instance, when confronting with topics unfamiliar to students, such as some workplace norms and customs, the teacher ought to offer learners more background information and special terms related, before heading to the class discussion and other language practice so that students of low proficiency could also follow up and actively participate.

Besides, it would help if the instructor could assign different types of tasks from time to time before class time, for instance, carrying out some research and interviews, aside from text analyzing, making up dialogues, and topic discussion, as an extrinsic motivation to inspire learners' devotion and investment. It could do good to their general comprehension as well.

Furthermore, as Brown (2004) stated "peer-assessment offer certain benefits: direct involvement of students in their own destiny, the encouragement of autonomy, and increased motivation because of their self-involvement" (p. 26), it may make more sense to encompass informal assessment and evaluation among group members in this experiment so as to boost students' degree of participation. And it may also function as a supportive assessing tool, since it is impossible for the teacher alone to comprehensively access the learners' pre-class work.

\section{Venues for Dissemination}

Findings of this research could be disseminated to conventional publications and journals, such as TESOL Quarterly and TESOL Journal. Presentations or talks at TESOL Convention and CATESOL Conference could also be possible. Moreover, teaching blogs, personal website, even Youtube sharing are practical venues as well. 


\section{Conclusion}

The present research delves into the effectiveness of the flipped classroom approach adopted in an English speaking class in China with the intention of stimulating motivation in learning and improving oral skills. Overall, the findings meet the researcher's anticipation, as the learners do spend more time on pre-class group learning, and the majority of the students become active members in class, taking part in classroom communicative activities and tasks enthusiastically. Besides, conceivable progress could be discerned from learners' class performance, the instructor's teaching logs and the final summative assessment results. Suggestions such as periodic rotation among the class, additional teacher-led instruction on difficult topics, and informal evaluation with group members are also put forward to help to further improve the teaching quality and learning effects in the future.

\section{References}

Allport, G. A. (1954). The nature of prejudice. New York: Addison-Wesley Publishing Co..

Brown, H. D., \& Abeywickrama, P. (2010). Language assessment: Principles and classroom practice. New York: Pearson Education.

Ormrod, J. E. (2013). Educational psychology: Developing learners (6th ed.). Upper Saddle River, NJ: Pearson.

Pettigrew, T. F. (1998). Intergroup contact theory. Annual Review of Psychology, 49(1), 65-85.

Senior, R. M. (2002). A class-centred approach to language teaching. ELT Journal, 56(4), 397-403.

Ways to make your teaching more effective. (n.d.). Retrieved from https://teaching.berkeley.edu/ways-make-your-teaching-more-effective

\section{Appendix}

\section{Interview Questions}

(1) What do you think of the outcome of students' group/pair learning prior to the class?

(2) Have you seen any changes in students' performance during the class? Do they actively participate in the tasks?

(3) Is there any progress in their oral speaking capabilities after adopting such a flipped approach?

(4) What is the hardest part of the implementation of the flipped classroom approach?

(5) Will you apply the approach to the teaching of other class next term?

Survey Questions

I think learning English is important to me.

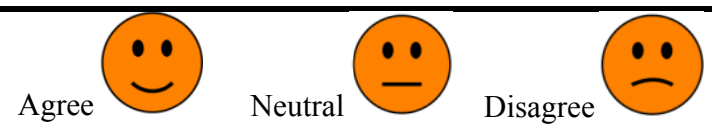

I am willing to further my English study.

I benefit a lot during group/pair study prior to class.

I like to participate in class activities.

I have more opportunities to practice English during the class.

I am more concentrated on the instruction in the class.

My spoken English improves after adopting this new strategy.

I would recommend this kind of teaching approach. 